\title{
Long-term survivorship of esophageal cancer patients treated with radical intent
}

\author{
Alex Agranovich MD FRCPC ${ }^{1}$, Colleen E McGahan MSc ${ }^{2}$, Anagha Gurjal MD ${ }^{3}$
}

\begin{abstract}
A Agranovich, CE McGahan, A Gurjal. Long-term survivorship of esophageal cancer patients treated with radical intent. Can J Gastroenterol 2008;22(4):393-398.
\end{abstract}

To investigate the recent trends in definitive management of esophageal cancer, the records of 138 consecutive patients treated with radical intent in a single institution between 1995 and 2003 were reviewed and analyzed. The median follow-up period was 5.7 years (range 1.1 to 10.4 years). Seventy-seven patients were treated with radiation therapy (RT) only and 61 with combined regimens (CRT), in which RT was combined with either radical surgery or chemotherapy, or both. The overall survival of the entire cohort was $32 \%$ over two years and $20 \%$ over five years. The survivorship in the RT group was $17 \%$ over two years and $5 \%$ over five years. In the CRT group, $51 \%$ and $35 \%$ survived over two and five years, respectively. From all the potential prognostic factors examined by univariate and multivariate analyses, only male sex and use of CRT were strongly associated with better survivorship. There was no significant difference in the outcomes among the different regimens of CRT. Survivorship was not affected by the location or histology of the tumour, clinical stage, dose of RT or use of endoluminal brachytherapy in addition to external beam RT. There was a greater tendency to use RT only more often in older patients, but patient age did not affect survivorship. The proportion of patients treated with CRT did not change significantly over the last versus the first four years of the observed period. Combined regimens are undoubtedly superior to RT as a single modality. The long-term survivorship of patients in a subgroup of our patients treated with combined modality protocols compared favourably with the previously reported results in the literature and specifically in prospective randomized trials. However, the optimal combined modality regimen is yet to be defined.

Key Words: Combined treatment regimens; Esophageal cancer; Radiotherapy

The mortality of patients with esophageal cancer remains

1 extremely high. Three-year survival of radical surgery (RS) alone varies greatly, from $6 \%$ to $26 \%$, based on prospective randomized studies $(1,2)$. The superiority of combined treatment regimens (CRTs), particularly those including chemotherapy, over radiation therapy (RT) alone and over RS alone is documented in only a few randomized studies (3-6). Considerable controversy still exists regarding the role of neoadjuvant RT, adjuvant RT and chemotherapy, and their potential to improve the outcomes of surgical resection $(2,7-10)$. The obectives of

\begin{abstract}
Survie à long terme des patients atteints de cancer de l'œsophage soumis à un traitement radical
\end{abstract}

Pour analyser les tendances récentes en matière de traitement radical pour le cancer de l'œsophage, les auteurs ont passé en revue et analysé les dossiers de 138 patients consécutifs traités de manière radicale dans un établissement, entre 1995 et 2003. La période de suivi médiane était de 5,7 ans (de 1,1 à 10,4 ans). Soixante-dix-sept patients ont été traités par radiothérapie (RT) seulement et 61 au moyen de schémas mixtes (CRT) au cours desquels la RT était combinée soit à une chirurgie radicale, soit à une chimiothérapie, soit aux deux. La survie globale de la cohorte entière a été de $32 \%$ à deux ans et de $20 \%$ à cinq ans. La survie du groupe sous RT a été de $17 \%$ à deux ans et de $5 \%$ à cinq ans, tandis que dans le groupe soumis à la CRT, $51 \%$ et $35 \%$ ont survécu deux et cinq ans, respectivement. De tous les facteurs pronostiques potentiels analysés par méthode uni- ou multivariée, seuls le sexe masculin et l'utilisation de la CRT ont été fortement associés à une meilleure survie. On n'a noté aucune différence significative quant à l'issue selon les différents schémas de CRT. La survie n'a pas subi d'influence de la localisation ou de l'histologie de la tumeur, du stade clinique, de la dose de RT ni de l'utilisation de brachythérapie endoluminale en plus du faisceau de RT externe. On a noté une tendance plus forte à l'utilisation de la RT seulement chez les sujets plus âgés, mais l'âge des patients n'a pas affecté la survie. La proportion de patients traités par CRT n'a pas changé significativement entre la première et la quatrième années de la période d'observation. Les schémas d'association ont été sans contredit supérieurs à la RT utilisée seule. La survie à long terme des patients dans un sous-groupe traités au moyen de protocoles thérapeutiques d'association s'est comparée favorablement aux résultats antérieurs rapportés dans la littérature et spécifiquement à ceux d'essais randomisés prospectifs. Par contre, le schéma d'association optimum reste à définir.

${ }^{1}$ Department of Radiation Oncology, British Columbia Cancer Agency, Fraser Valley Centre, Surrey; ${ }^{2}$ Department of Population and Preventive Oncology, British Columbia Cancer Agency, Vancouver Centre, Vancouver; ${ }^{3}$ Department of Medical Oncology, British Columbia Cancer

Agency, Fraser Valley Centre, Surrey, British Columbia

Correspondence and reprints: Dr Alex Agranovich, Department of Radiation Oncology, British Columbia Cancer Agency, 1375096 Avenue,

Surrey, British Columbia V3V 122. Telephone 604-930-4036, fax 604-930-4065, e-mail aagranov@bccancer.bc.ca

Received for publication September 28, 2007. Accepted December 10, 2007 
TABLE 1

Two schedules used to deliver chemotherapy (ChT) to esophageal cancer patients at the Fraser Valley Centre (Surrey, British Columbia), April 1, 1995 to December 31, 2003

\begin{tabular}{lllllllllllll}
\hline \multicolumn{1}{c}{ Week } \\
\hline Therapy & $\mathbf{1}$ & $\mathbf{2}$ & $\mathbf{3}$ & $\mathbf{4}$ & $\mathbf{5}$ & $\mathbf{6}$ & $\mathbf{7}$ & $\mathbf{8}$ & $\mathbf{9}$ & $\mathbf{1 0}$ & $\mathbf{1 1}$ & $\mathbf{1 2}$ \\
\hline Schedule 1 & & & & & & & & & & & \\
RT & $\mathrm{X}$ & $\mathrm{X}$ & $\mathrm{X}$ & $\mathrm{X}$ & $\mathrm{X}$ & & & & & & & \\
ChT & 1 & & & & $(2)$ & & & & 3 & & & 4 \\
Schedule 2 & & & & & & & & & & & \\
RT & & & X & X & X & X & X & & & & \\
ChT & 1 & & & 2 & & & & $(3)$ & & & & 4 \\
\hline
\end{tabular}

Each raw number in the ChT schedule represents the number of the cycle, and the numbers in parentheses indicate that the ChT cycle is optional based on the side effects. RT Radiation therapy; X Radiation therapy is given

April 1, 1995 and December 31, 2003 in a single institution (Fraser Valley Centre in Surrey, British Columbia).

The staging procedure included obtaining patient history and complete physical examination reports, laboratory results (ie, complete blood count, liver function tests, creatinine, electrolytes, carcinoembryonic antigen test for patients with adenocarcinoma), chest $\mathrm{x}$-ray and computed tomography scan of the chest and abdomen. Positron emission tomography (PET) scans were not readily available in the studied time period. The stage of esophageal cancer was determined based on clinical and radiological information, and on pathology reports for a subgroup of patients treated with RS. Although functional status has not always been documented, all of the patients in the study's cohort were ambulatory and RT was delivered almost exclusively on an outpatient basis, with the exception of short admissions for chemotherapy.

RT was given alone or in combination with chemotherapy. The total dose of external beam RT was no less than $40 \mathrm{~Gy}$ in 15 fractions over three weeks. High dose rate endoluminal brachytherapy as a boost was optional, given at a dose of 5 Gy to $15 \mathrm{~Gy}$.

The chemotherapy regimen consisted of 5-fluorouracil (5-FU) $1000 \mathrm{mg} / \mathrm{m}^{2} /$ day as a $96 \mathrm{~h}$ continuous infusion and cisplatin $25 \mathrm{mg} / \mathrm{m}^{2} /$ day as a $30 \mathrm{~min}$ continuous infusion. One of two schedules was used to deliver chemotherapy (Table 1). The second cycle of chemotherapy was eliminated if there was major toxicity.

RS procedures included either total thoracoabdominal esophagectomy or transhiatal esophagectomy with stomach mobilization and pull up. The patients suitable for RS were normally reassessed by computed tomography of the chest and abdomen, and underwent RS four to six weeks after completion of RT or RT plus chemotherapy.

RT alone was given to 77 patients. The CRTs consisted of RT plus chemotherapy ( $\mathrm{n}=26)$, RT followed by RS ( $\mathrm{n}=16), \mathrm{RT}$ plus chemotherapy followed by RS ( $n=12$ ) and RS followed by RT $(n=7)$. The patient and treatment characteristics are summarized in Table 2.

After completing their treatment, the patients were seen (with history and physical examination) every three to four months for the first two years and then every six months until five years. Laboratory and imaging studies were performed only if dictated by clinical presentation.
TABLE 2

Patient characteristics and treatment regimens

\begin{tabular}{|c|c|c|}
\hline Characteristic & $\mathbf{n}$ & $\%$ \\
\hline \multicolumn{3}{|l|}{ Age at diagnosis, years } \\
\hline$\leq 70$ & 77 & 55.8 \\
\hline$>70$ & 61 & 44.2 \\
\hline Mean (range) age, years & 68 (44 to 97$)$ & \\
\hline \multicolumn{3}{|l|}{ Sex } \\
\hline Female & 36 & 26.1 \\
\hline Male & 102 & 73.9 \\
\hline \multicolumn{3}{|l|}{ Disease site } \\
\hline Cardia & 30 & 21.7 \\
\hline Lower one-third & 68 & 49.3 \\
\hline Middle one-third & 32 & 23.2 \\
\hline Upper one-third & 7 & 5.1 \\
\hline Not otherwise specified & 1 & 0.7 \\
\hline \multicolumn{3}{|l|}{ Histology } \\
\hline Adenocarcinoma & 64 & 46.4 \\
\hline Squamous & 66 & 47.8 \\
\hline Other & 8 & 5.8 \\
\hline \multicolumn{3}{|l|}{ T stage } \\
\hline T1 & 25 & 18.1 \\
\hline T2 & 55 & 39.9 \\
\hline T3 & 33 & 23.9 \\
\hline$T X$ & 25 & 18.1 \\
\hline \multicolumn{3}{|l|}{ Nodal involvement } \\
\hline Yes & 29 & 21.0 \\
\hline No & 45 & 32.6 \\
\hline Unknown & 64 & 46.4 \\
\hline \multicolumn{3}{|l|}{ Treatment group } \\
\hline RT only & 77 & 55.8 \\
\hline RT then RS & 16 & 11.6 \\
\hline RS then RT & 7 & 5.1 \\
\hline $\mathrm{RT}+\mathrm{ChT}+\mathrm{RS}$ & 12 & 8.7 \\
\hline $\mathrm{RT}+\mathrm{ChT}$ & 26 & 18.8 \\
\hline \multicolumn{3}{|l|}{ Diagnosis year } \\
\hline 1995 to 1999 & 67 & 48.6 \\
\hline 2000 to 2003 & 71 & 51.4 \\
\hline \multicolumn{3}{|l|}{ Patient status } \\
\hline Alive & 32 & 23.2 \\
\hline Deceased & 106 & 76.8 \\
\hline \multicolumn{3}{|l|}{ Cause of death $(n=106)$} \\
\hline Disease specific & 98 & 92.5 \\
\hline Disease unrelated & 8 & 7.5 \\
\hline \multicolumn{3}{|l|}{ Type of RT } \\
\hline External only & 64 & 46.4 \\
\hline External + endoluminal brachytherapy & 74 & 53.6 \\
\hline \multicolumn{3}{|l|}{ Dose of external RT } \\
\hline $40 \mathrm{~Gy}$ & 79 & 57.2 \\
\hline$\geq 50 \mathrm{~Gy}$ & 59 & 42.8 \\
\hline \multicolumn{3}{|l|}{ Dose of endoluminal brachytherapy } \\
\hline 5 Gy (two doses) & 5 & 6.8 \\
\hline $10 \mathrm{~Gy}$ & 24 & 32.4 \\
\hline 15 Gy & 45 & 60.8 \\
\hline
\end{tabular}

ChT Chemotherapy; RS Radical surgery; RT Radiation therapy 


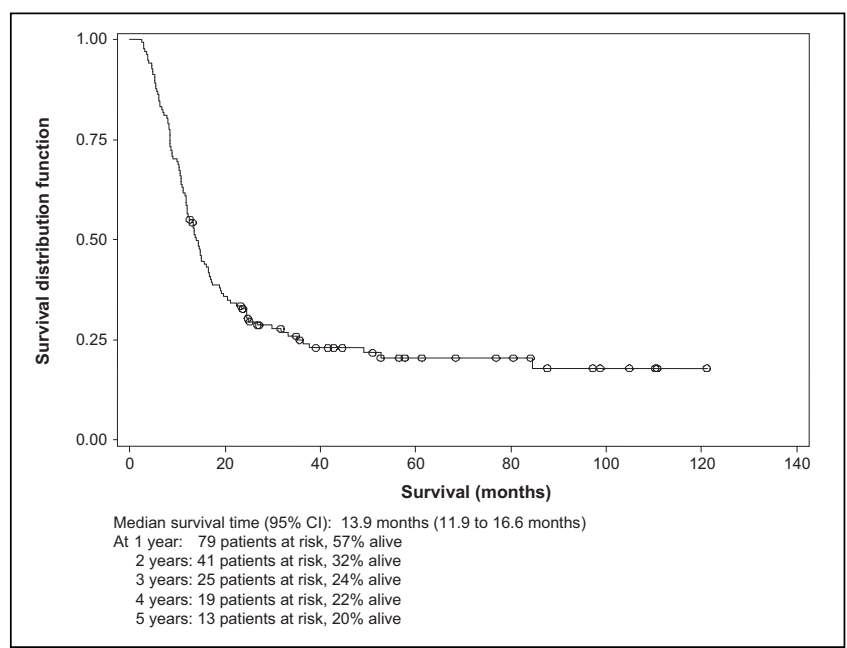

Figure 1) Overall survival of the esophageal cancer patient cohort at the Fraser Valley Centre (Surrey, British Columbia), April 1, 1995 to December 31, 2003

Subsequently, they were followed by annual correspondence with their general practitioners.

\section{Statistical methods}

Nonparametric estimates of the survivor functions were computed using the Kaplan-Meier method (SAS 9.1.3, SAS Institute Inc, USA) for each prognostic factor, and the logrank test was used to identify potential prognostic factors predictive of survival using a $10 \%$ significance level. Multivariate analysis was performed using the Cox regression model, including only significant prognostic factors from the univariate analysis. Scaled Schoenfeld residuals were calculated in $\mathrm{R}$ using the cox.zph function to check the assumption of proportional hazards. Forward selection was used to determine the final predictors of survival, using a $5 \%$ significance level.

\section{RESULTS}

The median survival time of the entire cohort (Figure 1) was 13.9 months (95\% CI 11.9 to 16.6 months).

With a median follow-up period of 5.7 years (range 1.1 to 10.4 years), the overall survival of the entire cohort was 32\% over two years and $20 \%$ over five years. In the subgroup of patients treated with RT only, the overall survival was $18 \%$ and less than 5\% over two and five years, respectively, compared with $49 \%$ and $35 \%$, respectively in the subgroup receiving CRTs.

At the end of the follow-up period, 32 patients were alive (23.2\%) and 106 were deceased (76.8\%). The median follow-up period for patients who were still alive was 6.2 years (range 2.2 to 10.4 years). Among the patients who died, only eight $(7.5 \%)$ of the deaths resulted from causes unrelated to esophageal cancer causes.

The overall median survival is expressed in months and the factors that could potentially have an impact on it are summarized in Table 3.

The multivariate Cox regression model for survival consisted of four potential prognostic factors - sex, disease site, $\mathrm{T}$ stage and treatment regimen (RT versus CRT). Using the
TABLE 3

Overall median survival of patients and the factors that could potentially have an impact on survival

\begin{tabular}{|c|c|c|c|}
\hline \multirow[b]{2}{*}{ Factor } & \multicolumn{2}{|c|}{ Survival, months } & \multirow[b]{2}{*}{$\mathbf{P}$} \\
\hline & Median & $95 \% \mathrm{Cl}$ & \\
\hline \multicolumn{4}{|l|}{ Age at diagnosis, years } \\
\hline$\leq 70$ & 14.8 & 11.8 to 20.5 & 0.388 \\
\hline$>70$ & 13.6 & 11.3 to 16.6 & \\
\hline \multicolumn{4}{|l|}{ Sex } \\
\hline Female & 11.8 & 8.3 to 15.7 & 0.038 \\
\hline Male & 14.8 & 13.1 to 19.2 & \\
\hline \multicolumn{4}{|l|}{ Disease site } \\
\hline Cardia/lower & 14.8 & 13.1 to 19.2 & 0.080 \\
\hline Middle/upper & 10.9 & 8.4 to 16.6 & \\
\hline \multicolumn{4}{|l|}{ Histology } \\
\hline Adenocarcinoma/other & 13.9 & 11.8 to 19.1 & 0.613 \\
\hline Squamous & 14.4 & 11.3 to 17.3 & \\
\hline \multicolumn{4}{|l|}{ T stage } \\
\hline $\mathrm{TX} / \mathrm{T} 1 / \mathrm{T} 2$ & 13.2 & 10.9 to 16.4 & 0.076 \\
\hline $\mathrm{T} 3$ & 17.3 & 13.8 to $\mathrm{NE}^{*}$ & \\
\hline \multicolumn{4}{|l|}{ Nodal involvement } \\
\hline Yes & 15.1 & 11.8 to 19.2 & 0.600 \\
\hline No & 13.3 & 10.8 to 19.1 & \\
\hline Unknown & 13.6 & 10.9 to 22.4 & \\
\hline \multicolumn{4}{|l|}{ Treatment regimens } \\
\hline RT only & 11.8 & 10.3 to 13.6 & $<0.0001$ \\
\hline All others & 23.5 & 14.8 to 84.6 & \\
\hline RT only & 11.8 & 10.3 to 13.6 & \\
\hline $\mathrm{RT}+\mathrm{RS}$ & $24.9^{\dagger}$ & 14.8 to $\mathrm{NE}^{*}$ & \\
\hline $\mathrm{RT}+\mathrm{ChT}$ & 14.5 & 8.9 to $\mathrm{NE}^{*}$ & \\
\hline $\mathrm{RT}+\mathrm{ChT}+\mathrm{RS}$ & 33.3 & 20.5 to $\mathrm{NE}^{*}$ & \\
\hline \multicolumn{4}{|c|}{ Number of treatment modalities } \\
\hline 1 & 11.8 & 10.3 to 13.6 & \\
\hline 2 & 19.2 & 14.3 to 35.1 & \\
\hline 3 & 33.3 & 20.5 to $\mathrm{NE}^{*}$ & \\
\hline \multicolumn{4}{|l|}{ Diagnosis year } \\
\hline 1995 to 1999 & 13.9 & 11.8 to 16.6 & 0.447 \\
\hline 2000 to 2003 & 14.6 & 11.1 to 23.5 & \\
\hline \multicolumn{4}{|l|}{ Type of RT (RT only group) } \\
\hline External only & 14.8 & 11.8 to 18.8 & 0.942 \\
\hline $\begin{array}{l}\text { External + endoluminal } \\
\text { brachytherapy }\end{array}$ & 13.6 & 11.1 to 19.1 & \\
\hline \multicolumn{4}{|l|}{ Total dose of external RT } \\
\hline$<50$ Gy & 13.3 & 10.7 to 16.4 & 0.119 \\
\hline$\geq 50 \mathrm{~Gy}$ & 15.1 & 12.1 to 24.2 & \\
\hline
\end{tabular}

$P<0.05$ was defined as significant. *Not estimable (NE) (ie, the upper limit of the $95 \% \mathrm{Cl}$ for the median survival was not reached); ${ }^{\dagger}$ Because the number of patients in the subgroup treated with surgery followed by radiation therapy $(R T)$ was very small $(n=7)$, for the purpose of the analysis, it was combined with the subgroup treated with RT followed by surgery $(n=16)$. ChT Chemotherapy; RS Radical surgery

forward selection method, the final model showed that males had a significantly better survival than females $(P=0.044$, hazard ratio of 0.65 [range 0.42 to 0.99 ]). CRTs as opposed to RT alone, was the greatest influential factor in better survivorship $(P<0.0001$, hazard ratio of 0.43 [range 0.29 to 0.65 ]). Figures 2 


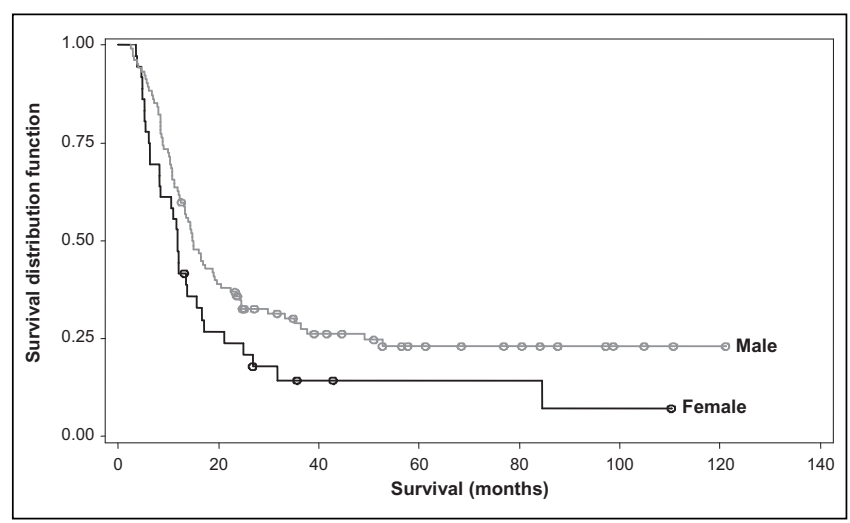

Figure 2) Overall survival of patients at the Fraser Valley Centre (Surrey, British Columbia) between April 1, 1995 and December 31, 2003, stratified by sex

and 3 show plots of the survivor distribution for sex and treatment regimen, respectively.

The number of complete pathological responses were also examined, as determined by the absence of a viable tumour in the surgical specimen. In 28 patients who underwent RS after preoperative RT or RT plus chemotherapy, the percentage of pathologically proven complete responses was very similar: $37.5 \%$ (six of 16 ) and $33.3 \%$ (four of 12 ) in preoperative RT and RT plus chemotherapy subgroups, respectively.

\section{RT toxicity}

Neither esophageal perforation nor bleeding related to RT were encountered in the early and late post-RT period.

Among 25 patients who survived three years or longer, benign stricture (without evidence of tumour recurrence), which required regular or episodic esophageal dilation, developed in four patients (16\%). The nutritional status of all four patients remained good.

\section{Chemotherapy toxicity}

Data were examined for patients who underwent concurrent chemotherapy and RT ( $n=38)$. An acute toxicity was more significant, with no patients being diagnosed with chronic problems that could be attributed to chemotherapy. Patients experienced varying degrees of nausea and emesis ranging from mild to severe, resulting in dehydration, and four patients required intravenous fluids. Esophagitis was also a common side effect, but it is impossible to evaluate whether chemotherapy or RT was the predominant cause. Three patients experienced coronary artery spasm and one death, secondary to myocardial infarction, occurred. Febrile neutropenia was encountered in one patient. One patient died of a cerebrovascular accident within one week of completing treatment.

\section{DISCUSSION}

Our retrospective study confirmed that the use of CRTs is superior to RT only, for the treatment of esophageal cancer. However, the question remains unanswered as to what constitutes an optimal combined regimen.

One of the potential reasons for a great variability of reported results in esophageal cancer may lie in the limitation of clinical and radiological staging methods used in

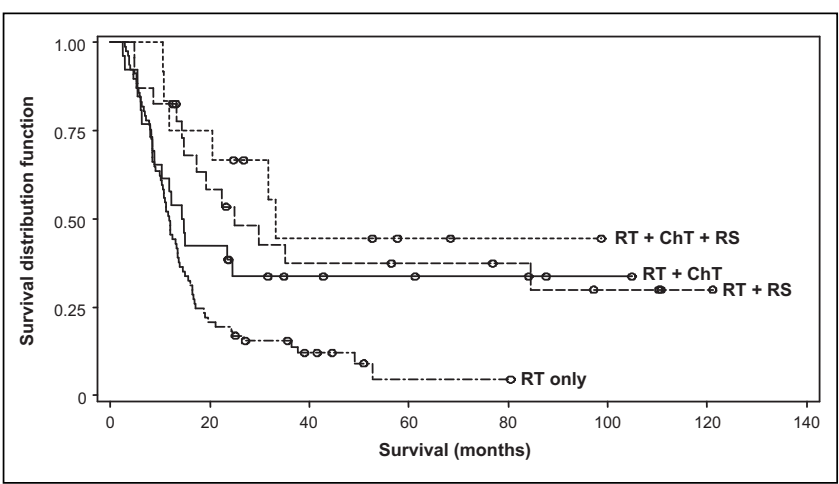

Figure 3) Overall survival of patients at the Fraser Valley Centre (Surrey, British Columbia) between April 1, 1995 and December 31, stratified by treatment subgroup. ChT Chemotherapy; RS Radical surgery; RT Radiation therapy

selecting patients for definitive treatment. Our study and reported randomized studies of esophageal cancer were performed at a time when PET scans were not widely available for staging esophageal cancer patients. Literature reports indicate the usefulness of PET in staging esophageal cancer by detecting the locoregional extent and distant spread of esophageal cancer (11). Currently, PET scans are routinely used for staging of esophageal cancer at the British Columbia Cancer Agency. Although it may have an impact on the process of selection of patients suitable for radical treatments and improvement of their outcomes, it may not necessarily reduce the overall mortality of esophageal cancer patients because of a potential shift in staging (ie, detecting more patients with distant metastases). Alternatively, there are reports $(12,13)$ of PET scan and endoscopic ultrasound use for RT planning in esophageal cancer, which may lead to better results of this treatment modality.

To correlate our results with the published literature, we reviewed data currently available in the Cochrane database, as well as systematic reviews of available prospective randomized trials using RT $(7-10,14)$. There was no definitive evidence, based on meta-analysis of existing randomized trials, of the benefits of preoperative and postoperative RT. However, there was good evidence for the superiority of concurrent RT plus chemotherapy over RT alone, mainly based on Radiation Therapy Oncology Group (RTOG) 85-01 study results $(3,4)$. There is also some evidence of an advantage of choosing preoperative RT plus chemotherapy followed by RS versus RS alone, again mainly based on a single and rather small, strongly positive study reported by Walsh et al (1) and two meta-analyses $(15,16)$ that concluded that combined regimens with preoperative RT plus chemotherapy improves three-year survival and reduces three-year mortality compared with surgery alone. In the study conducted by Walsh et al, the survivorship in surgery alone was only $6 \%$ over three years. In comparison, the three-year survivorship after surgery alone, reported by Kelsen et al (2) (which was based on an intergroup randomized study conducted by the leading North American oncology centres), was 26\% (ie, it was very similar to the RT plus chemotherapy arm of the RTOG 85-01 study). The question that remains unanswered is whether RT plus chemotherapy could achieve similar results to those of RS alone. Our study could not address this question because the 
studied cohort did not have a subgroup treated with RS only (some of these patients are not routinely referred to the cancer clinic).

The present study's treatment results were compared with those achieved in the above mentioned prospective randomized controlled studies (Table 4).

The long-term treatment results in the Fraser Valley Centre cohort is favourably compared with the best results achieved in two prospective randomized trials, which set standards for treatment of esophageal cancer in North America and Europe. Because of the small number of patients in some of the treatment subgroups, we cannot demonstrate any decisive superiority of one of the CRTs. It also may reflect the heterogeneity of esophageal cancer patients and their variable suitability for more aggressive therapeutic modalities.

An optimal chemotherapy regimen for esophageal cancer is yet to be developed. The MD Anderson Cancer Center (Houston, Texas, USA) used an induction chemotherapy, with two cycles being administered before concurrent chemotherapy and RT. Patients who received this form of treatment had a significantly better three-year survival rate $(59 \%$ versus $41 \%$ ) (17).

To date, there are no unequivocally convincing data regarding an optimal regimen of RT for esophageal cancer (8). Perhaps even potentially superior locoregional control, which might be achieved by certain RT regimens, is obscured by a high risk of systemic failure and, thus, does not lead to a better survival rate of esophageal cancer patients. In the studied group of patients, we frequently used a three-week course of RT in patients treated with RT alone or RT followed by RS. In approximately one-half of the patients, an endoluminal brachytherapy boost was added. The pathologically complete response rate in our subgroup treated with RT followed by RS was quite respectable $(37.5 \%)$ and compared favourably with that reported by Walsh et al (25\%) (1). In patients treated with a combination of RT and chemotherapy, a five-week course was used, similar to the RTOG 85-01 trial. For those patients who underwent a subsequent surgery, a complete pathological response was observed in $33.3 \%$ of the patients. It demonstrates the effectiveness of the chosen RT regimens in one-third of the patients. At the same time, the locoregional control in the remaining two-thirds of the patients remains unsatisfactory and leaves room for improvement.

There is uncertainty regarding the value of endoluminal brachytherapy in the management of esophageal cancer, specifically high dose rate brachytherapy. We found only one prospective randomized study (18) addressing this issue. It

\section{REFERENCES}

1. Walsh TN, Noonan N, Hollywood D, Kelly A, Keeling N, Hennessy TP. A comparison of multimodal therapy and surgery for esophageal adenocarcinoma. N Engl J Med 1996;335:462-7. (Erratum in 1999;341:384).

2. Kelsen DP, Ginsberg R, Pajak TF, et al. Chemotherapy followed by surgery compared with surgery alone for localized esophageal cancer. N Engl J Med 1998;339:1979-84.

3. Herskovic A, Martz K, al-Sarraf M, et al. Combined chemotherapy and radiotherapy compared with radiotherapy alone in patients with cancer of the esophagus. $\mathrm{N}$ Engl J Med 1992;326:1593-8

4. al-Sarraf M, Martz K, Herskovic A, et al. Progress report of combined chemoradiotherapy versus radiotherapy alone in patients with esophageal cancer: An intergroup study. J Clin Oncol 1997;15:277-84. (Erratum in 1997;15:866).
TABLE 4

Comparison of the present study results with previous prospective randomized controlled studies

\begin{tabular}{lcccccc}
\hline & \multicolumn{2}{c}{ RTOG 85-01, } \\
& RT=129 & CRT & RS & CRT & RT & CRT \\
\hline Survival & 10 & 36 & 26 & 37 & 18 & 49 \\
\hline Two-year, \% & 0 & 27 & 6 & 32 & $<5$ & 35 \\
Three- and five-year*, \% & 0 & & & & \multicolumn{2}{c}{$\begin{array}{c}\text { FVC, } \\
\text { ne138 }\end{array}$} \\
\hline
\end{tabular}

*Three-year survival was determined by Walsh et al (1) and five-year survival was determined by the Radiation Therapy Oncology Group (RTOG) (3) and the present study at the Fraser Valley Centre (FVC) in Surrey, British Columbia. CRT Combined regimens; RS Radical surgery; RT Radiation therapy

demonstrated an improvement in cause-specific survival in a small subset of esophageal cancer patients (20 of 43) whose tumours were less than $5 \mathrm{~cm}$ in length. However, there was no difference in overall survival for the entire cohort in that study. Obviously, it is insufficient to claim that endoluminal brachytherapy is more beneficial than an extra dose of external RT. Traditionally, endoluminal brachytherapy has been used, because it is considered to be a fast and effective method to relieve obstructive symptoms. In our analysis, we also could not demonstrate any improvement in overall survival with the addition of brachytherapy. At the same time, we found it to be totally safe and was not associated with an increased risk for acute or late toxicity as reported in the RTOG phase I/II study (19).

\section{SUMMARY}

In the large group of patients with esophageal cancer treated with radical intent, apart from the patients' sex, the most important prognostic factor that positively influenced longterm survivorship was the use of CRTs. With the use of CRTs, nearly one-third of esophageal cancer patients with locoregional disease can be cured. In the present study, we were unable to identify which particular regimen is superior. This question can be answered by conducting and analyzing the results of properly designed prospective randomized trials.

ACKNOWLEDGEMENTS: The authors thank all Fraser Valley Centre members who are involved in the management of esophageal cancer patients. Special thanks to Ms Linda Douglas for the preparation of the manuscript and to Mr Richard Sobel for editing the commentary and facilitating approval of the study by the Research Ethics Board.

5. Medical Research Council Oesophageal Cancer Working Group. Surgical resection with or without preoperative chemotherapy in oesophageal cancer: A randomised controlled trial. Lancet 2002;359:1727-33

6. Cunningham D, Allum WH, Stenning SP, et al. Perioperative chemotherapy versus surgery alone for resectable gastroesophageal cancer. N Engl J Med 2006;355:11-20.

7. Arnott SJ, Duncan W, Gignoux M, et al. Preoperative radiotherapy for esophageal carcinoma. Cochrane Database Syst Rev 2005:CD001799.

8. Ask A, Albertsson M, Järhult J, Cavallin-Stahl E. A systematic overview of radiation therapy effects in oesophageal cancer. Acta Oncol 2003;42:462-75.

9. Malthaner RA, Collin S, Fenlon D. Preoperative chemotherapy for resectable thoracic esophageal cancer. Cochrane Database Syst Rev 2006:CD001556 
10. Visser BC, Venook AP, Patti MG. Adjuvant and neoadjuvant therapy for esophageal cancer: A critical reappraisal. Surg Oncol 2003;12:1-7.

11. van Westreenen HL, Westerterp M, Bossuyt PM, et al. Systematic review of the staging performance of $18 \mathrm{~F}$-fluorodeoxyglucose positron emission tomography in esophageal cancer. J Clin Oncol 2004:22:3805-12

12. Vesprini D, Ung Y, Kamra J, et al. The impact of 18fluorodeoxyglucose positron emission tomography (FDG-PET) on radiotherapy planning in carcinoma of the esophagus. Radiother Oncol 2006;80(Suppl 1):S21. (Abst)

13. Thomas E, Crellin A, Harris K, Swift S, Montefiore DS. The role of endoscopic ultrasound (EUS) in planning radiotherapy target volumes for oesophageal cancer. Radiother Oncol 2004;73:149-51

14. Wong R, Malthaner R. Combined chemotherapy and radiotherapy (without surgery) compared with radiotherapy alone in localized carcinoma of the esophagus. Cochrane Database Syst Rev 2006:CD002092.

15. Urschel JD, Vasan H. A meta-analysis of randomized controlled trials that compared neoadjuvant chemoradiation and surgery to surgery alone for resectable esopageal cancer. Am J Surg 2003; 185:538-43.

16. Fiorica F, Di Bona D, Schepis F, et al. Preoperative chemoradiotherapy for oesophageal cancer: A systematic review and meta-analysis. Gut 2004:53:925-30

17. Malaisrie SC, Hofstetter WL, Correa AM, et al. The addition of induction chemotherapy to preoperative, concurrent chemoradiotherapy improves tumor response in patients with esophageal adenocarcinoma. Cancer 2006;107:967-74.

18. Okawa T, Dokiya T, Nishio M, Hishikawa Y, Morita K. Multi-institutional randomized trial of external radiotherapy with and without intraluminal brachytherapy for esophageal cancer in Japan. Japanese Society of Therapeutic Radiology and Oncology (JASTRO) Study Group. Int J Radiat Oncol Biol Phys 1999;45:623-8.

19. Gaspar LE, Winter K, Kocha WI, Coia LR, Herskovic A, Graham M. A phase I/II study of external beam radiation, brachytherapy, and concurrent chemotherapy for patients with localized carcinoma of the esophagus (Radiation Therapy Oncology Group Study 9207): Final report. Cancer 2000;88:988-95. 


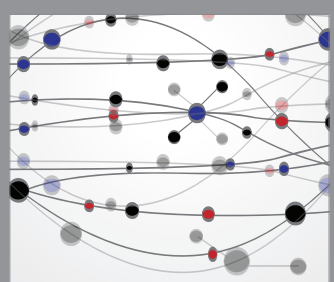

The Scientific World Journal
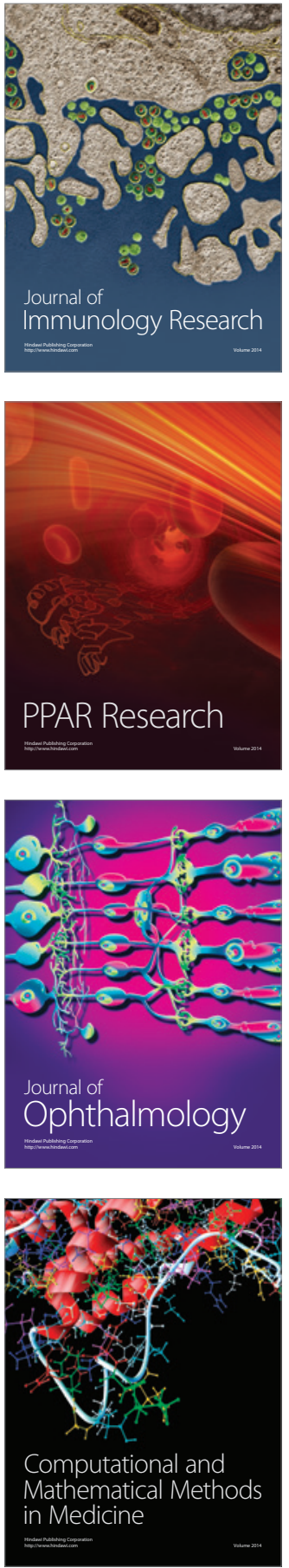

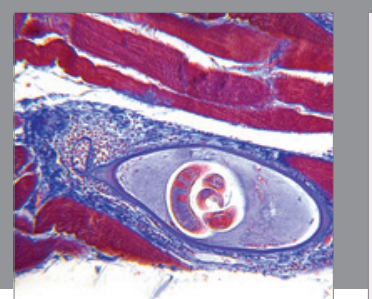

Gastroenterology Research and Practice

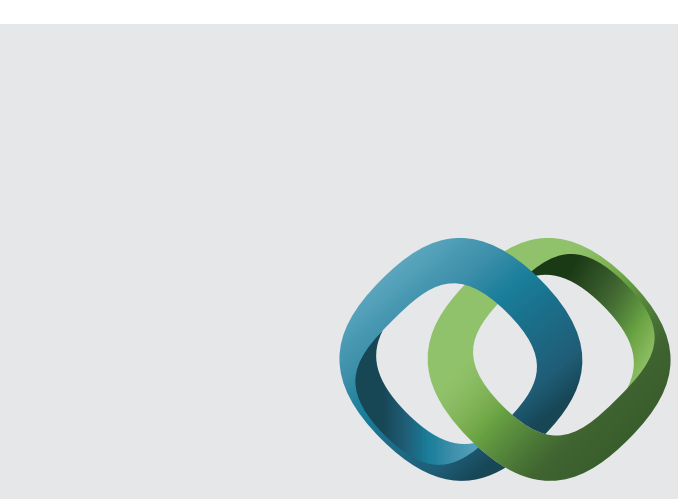

\section{Hindawi}

Submit your manuscripts at

http://www.hindawi.com
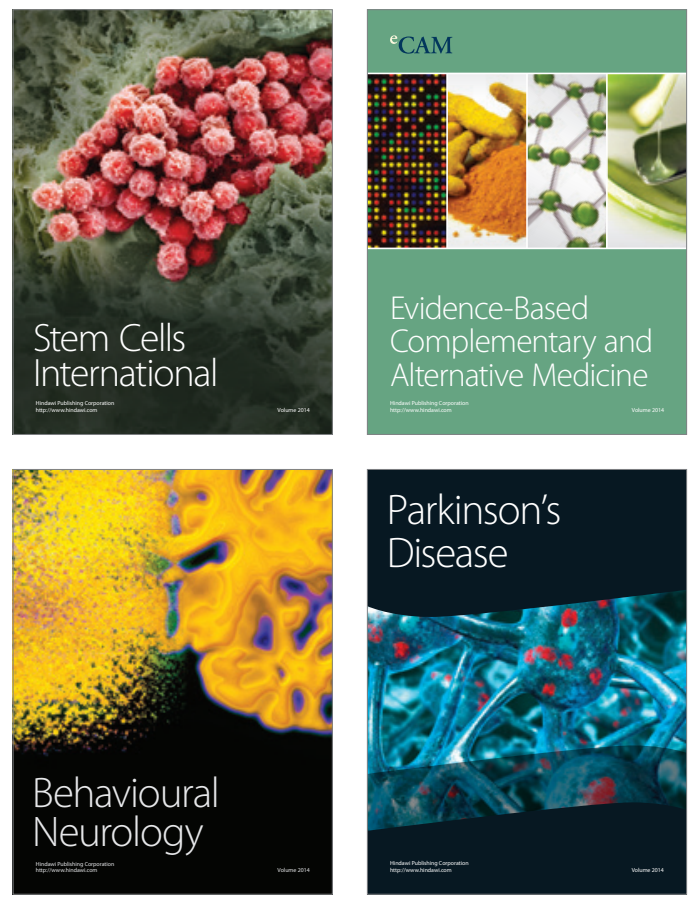
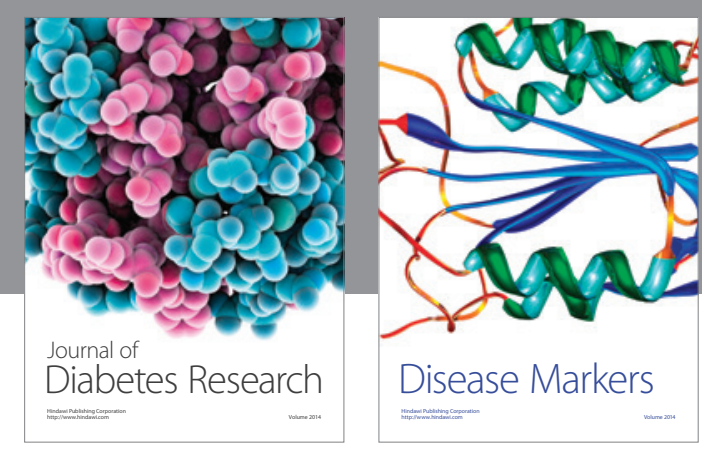

Disease Markers
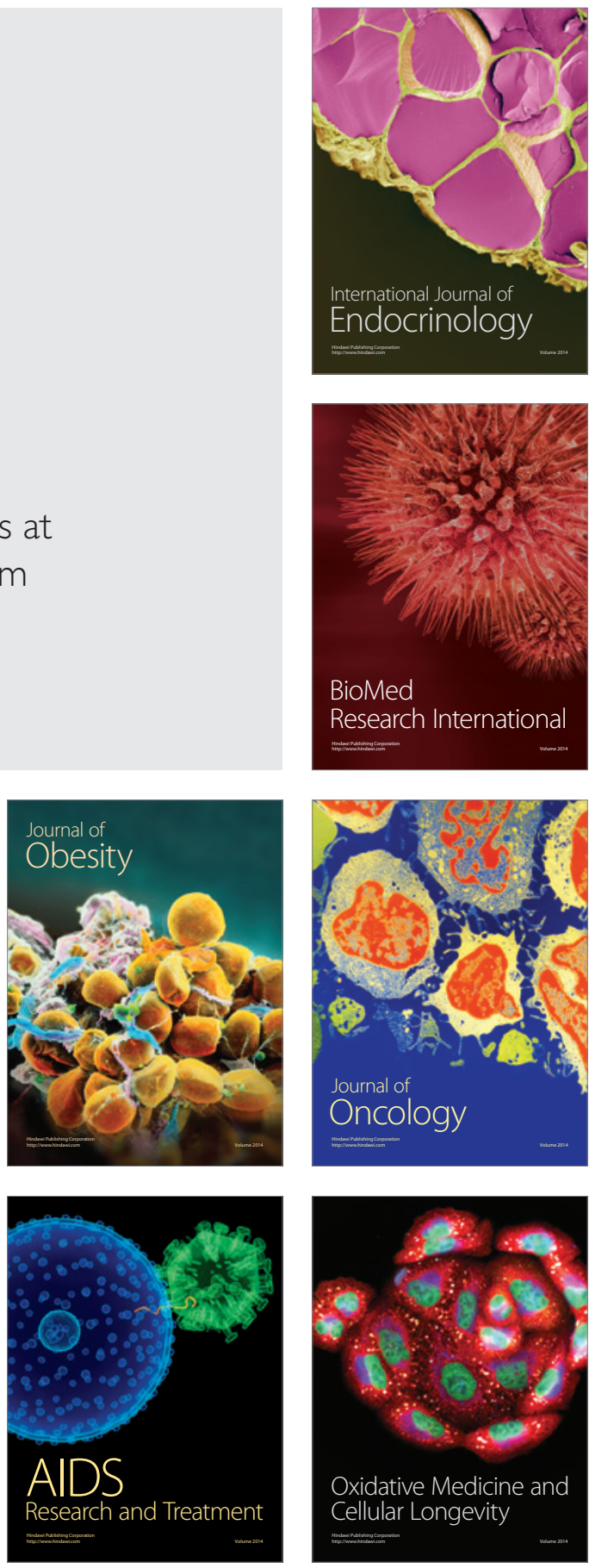